Johnson \& Wales University

ScholarsArchive@JWU

College of Business Faculty Publications and

Research

College of Business

$2-28-2020$

Measuring the Impact of Cause-Related Marketing: A MetaAnalysis of Nonprofit and For-profit Alliance Campaigns

Michelle M. Rego

Mark A. Hamilton

Dana Rogers

Follow this and additional works at: https://scholarsarchive.jwu.edu/mgmt_fac

Part of the Advertising and Promotion Management Commons 


\section{Measuring the Impact of Cause-Related Marketing: A Meta-Analysis of Nonprofit and For-profit Alliance Campaigns}

\section{Michelle M. Rego, Mark A. Hamilton \& Dana Rogers}

To cite this article: Michelle M. Rego, Mark A. Hamilton \& Dana Rogers (2020): Measuring the Impact of Cause-Related Marketing: A Meta-Analysis of Nonprofit and For-profit Alliance Campaigns, Journal of Nonprofit \& Public Sector Marketing, DOI: $10.1080 / 10495142.2020 .1726253$

To link to this article: https://doi.org/10.1080/10495142.2020.1726253

\section{Published online: 28 Feb 2020.}

Submit your article to this journal $\widetilde{ }$

Q View related articles $\asymp$

View Crossmark data $\nearrow$ 


\title{
Measuring the Impact of Cause-Related Marketing: A Meta-Analysis of Nonprofit and For-profit Alliance Campaigns
}

\author{
Michelle M. Rego (10), Mark A. Hamilton ${ }^{\mathrm{a}}{ }^{\mathrm{b}}$, and Dana Rogers ${ }^{\mathrm{c}}$ \\ aMarketing Department, Johnson \& Wales University, Providence, Rhode Island, USA; ${ }^{\circ}$ Communication \\ Department, University of Connecticut, Storrs, Connecticut, USA; 'Communication Department, \\ Southern Connecticut State University, New Haven, Connecticut, USA
}

\begin{abstract}
Cause-related marketing (CRM) campaigns are a type of joint venture between a business concern and a nonprofit organization. To determine effect sizes for these campaigns, a series of bivariate meta-analyses were conducted using a random effects assumption. Results included the effect of CRM advertising on brand attitudes, $r=.248,95 \% \mathrm{Cl}(0.189,0.373)$, and purchase intentions, $r=.277,95 \% \mathrm{Cl}(0.141,0.404)$, and the effect of cause-brand fit on brand attitudes, $r=.239,95 \% \mathrm{Cl}$ $(0.167,0.309)$, and purchase intentions, $r=.319,95 \% \mathrm{Cl}(0.206$, .423). Unfortunately for nonprofit organizations, none of the seven meta-analyses conducted found any effect for the study characteristic, type of cause (generic or branded company). Thus, the contribution of a specific nonprofit organization's brand did not have a significant impact on consumer attitudes or behavioral intentions to purchase CRM products.
\end{abstract}

\section{KEYWORDS}

Cause-related marketing; cause-brand fit; cause involvement; meta-analysis

Over 35 years ago, the field of cause-related marketing (CRM) began as a new type of joint venture between a business concern and a nonprofit organization. CRM ventures link such organizations in the sharing of their publics and outcomes, as well as the risks and benefits of the association (Barnes, 1991). Since the marketers at American Express coined the expression in 1983, consumers have generally embraced the idea of cause-related marketing (CRM) and its combination of economic and social objectives (Barnes, 1991; Caesar, 1986; Varadarajan \& Menon, 1988). According to the 2017 Cone Communications CSR Study, 55 percent of consumers in the United States reported purchasing a product associated with a cause in the past 12 months - an increase of over 170 percent since 1993 (Cone, 2017).

Global consumers are also increasing in their support for cause-related marketing. According to Nielsen (2014) global consumer survey, 55 percent

CONTACT Michelle M. Rego Michelle.Rego@jwu.edu E Johnson \& Wales University, 8 Abbott Park Place, Providence, RI 02903

The paper is the first publication resulting from research conducted as part of a doctoral dissertation: https://opencommons.uconn.edu/dissertations/1678. It was presented as a conference paper (top 3 paper award, advertising division) at the AEJMC 2018 Annual Conference, August 6-8, Washington, D.C. 
of approximately 30,000 participants from 60 countries responded that they are "willing to pay extra for products and services from companies that are committed to positive social and environmental impact" (p. 5). This willingness to pay extra represents a steady trend, from 45 percent in 2011, to 50 percent in 2012 to 55 percent in 2014 (Nielsen, 2014). In addition, causerelated academic research can be found all around the world. A literature review by Natarajan, Balasubramaniam, and Jublee (2016) discovered 300 peer-reviewed articles relating to CRM across 40 countries. The authors identified a range of research themes such as cause-fit, partnership dynamics, and consumer attitudes and behavior, which supported earlier findings (Guerreiro, Rita, \& Trigueiros, 2015).

Although several literature reviews have been conducted on the topic (Guerreiro et al., 2015; Lafferty, Lueth, \& McCafferty, 2016; Natarajan et al., 2016), no published quantitative summary of empirical research is available for the effect of advertising campaigns that promote causes (vs. non-cause campaigns) on brand attitudes and purchase intentions. A meta-analysis is therefore needed to calculate the weighted mean of advertising effect sizes (ES) in this field, and to explain the variance in ES across a global body of research.

\section{Rationale for meta-analytic review}

The purpose of this meta-analytic review is to identify all available causerelated marketing studies that examine the effects of perceptions, norms and beliefs on global consumer attitudes and purchase intentions, and to analyze differences found across these CRM campaigns. The goal of this analysis is to determine the strength and direction of relationships between CRM campaign variables in order to contribute to future academic research in the field of cause-related marketing, as well as CRM campaign strategies in the nonprofit and for-profit sectors worldwide.

In addition to examining the effects of cause-related advertising vs. non-causerelated advertising on brand attitudes and purchase intentions, variables of particular interest in this analysis include cause-brand fit, or the connection between the nonprofit and for-profit brands (; Ellen, Mohr, \& Webb, 2000; Lafferty, 2009; Nan \& Heo, 2007; Pracejus \& Olsen, 2004) and cause involvement or the level of importance the consumer has for the cause (; Hajjat, 2003; Hyllegard, Yan, Ogle, \& Attmann, 2010). In addition, this study is interested in measuring the effect of campaign messages that include a nonprofit brand versus a generic cause.

\section{The nature of cause-related marketing}

A widely used definition of cause marketing by Varadarajan and Menon (1988) that was selected to guide this analysis, states that cause-related marketing is "a process of formulating and implementing marketing activities 
that are characterized by an offer from the firm to contribute a specified amount to a designated cause when customers engage in revenue-providing exchanges that satisfy organizational and individual objectives," (p. 60). The success of these marketing activities is typically measured by improvements in brand attitudes and intentions to purchase CRM products.

According to the IEG Sponsorship Report, when marketing executives were asked which performance metrics were most important in evaluating their relationship with a cause (IEG, 2016) the top responses included attitudes toward the brand (86\%), brand awareness (81\%) and product/brand sales (66\%). CRM scholars have demonstrated a parallel approach, measuring both attitudes and purchase intentions as dependent variables (Galan-Ladero, Galera-Casquet, Valero-Amaro, \& Barroso-Mendez, 2013; Grau \& Folse, 2007; Hajjat, 2003; Lafferty, 2009).

\section{Theoretical perspectives}

A literature review by Lafferty et al. (2016) found that the theory of planned behavior (TPB) was used in dozens of studies in the area of cause-related marketing to guide their examination of the influence of culture, social norms, and beliefs on consumer attitudes and intentions to support CRM campaigns. Originally the theory of reasoned action (TRA), the theory was founded on three central premises: (1) that behavior can be predicted reliably by behavioral intentions, (2) that those intentions can be predicted by attitudes, and (3) that intentions can be predicted by subjective norms (Ajzen \& Fishbein, 1980). A meta-analysis by Armitage and Conner (2001) of 185 independent empirical tests of TRA found a medium-large effect size (Cohen, 1992) for behavioral intention $(r=.40)$. Subjective norms represent the perception that important others think the individual should or should not perform the given behavior (Ajzen \& Fishbein, 1980; Fishbein \& Ajzen, 1973). The theory of planned behavior (Ajzen, 1985) is an extension of TRA (Ajzen \& Fishbein, 1980; Fishbein \& Ajzen, 1973), adding a third element to the model: perceived behavioral control (Ajzen, 1985). Perceived behavioral control (PBC) was defined by Ajzen (1985) as the extent to which individuals feel that they have are capable of performing a certain behavior. This meta-analysis of global cause-related advertising is primarily concerned with campaign variables associated with social norms, perceptions and beliefs that influence consumer attitudes and purchase intentions.

\section{CRM effects: attitudes and behavioral intentions}

\section{Attitudes}

Attitudes can be defined as the degree to which an individual has favorable or unfavorable evaluations of an object (Fishbein, 1963). These attitudes are 
influenced by a variety of beliefs. According to Fishbein (1963), those beliefs with the highest subjective probability and greatest evaluative consequences should have the greatest influence on attitudes. Studies in cause-related marketing across the globe have found that advertising campaigns that include a CRM offer have a positive effect on consumer attitudes (BignéAlcañiz, Currás-Pérez, Ruiz-Mafé, \& Sanz-Blas, 2012; Boenigk \& Schuchardt, 2013; Chang \& Cheng, 2015; Chang \& Liu, 2012; Samu \& Wymer, 2009).

\section{Purchase intentions}

Purchase intention was also identified as a dependent variable in a wide range of CRM campaign studies (Aggarwal \& Singh, 2017; Arora \& Henderson, 2007; Bae, 2016; Berger, Cunningham, \& Kozinets, 1999; Chang, 2012b; Goldsmith \& Yimin, 2014; Kumar \& Bansal, 2017; Landreth, 2002; Westberg \& Pope, 2014). The following hypotheses reflect the findings expected from a meta-analysis of this literature.

H1: Cause-related advertising campaigns will increase favorable consumer attitudes toward a) sponsoring brands and b) intentions to purchase CRM products.

\section{Consumer perceptions: cause-brand fit}

Cause-brand fit is a term that refers to the consumer's perception of the connection or link (Lafferty, Goldsmith \& Hult, 2004; Lafferty \& Edmondson, 2009) between the cause and the brand in a specific CRM campaign. A "good fit" is measured by the extent to which consumers perceive the alliance to be logical, complementary and congruent (Bigné-Alcañiz et al., 2012; Steckstor, 2011). Studies have found that cause-brand fit moderates the effect of CRM advertising on consumer attitudes such that high fit increases favorable attitudes toward brand outcomes (Hou, Du, \& Li, 2008; Nan \& Heo, 2007).

H2: Cause-brand fit increases a) favorable attitudes toward sponsoring brands and b) purchase intentions.

H3: Cause involvement will increase a) favorable attitudes toward sponsoring brands and $b$ ) intentions to purchase CRM products.

\section{Beliefs: cause involvement}

Cause involvement can be defined as the level of personal importance based on individual needs, values, and interests (Zaichkowsky, 1985) or the degree to which consumers find a cause personally relevant to them (Grau \& Folse, 2007). 
Several researchers have concluded that cause involvement has a positive effect on cause-brand attitudes and purchase intentions (Berger et al., 1999; Patel, Gadhavi, and Shukla, 2016; Steckstor, 2011), and perceptions of cause-brand fit (; Hajjat, 2003; Hyllegard, Yan, Ogle, \& Attmann, 2010).

\section{Beliefs: skepticism}

An early CRM study by Webb \& Mohr, (1998) categorized consumers as skeptics, balancers, attribute oriented, or socially concerned, according to their responses of CRM knowledge level, attitude toward the brand, buying behavior and perception of motives. In the context of cause-related marketing programs, skepticism can be defined as the tendency of a consumer toward disbelief or questioning of a company's motives for entering an alliance with a nonprofit (Mohr, Eroglu, \& Ellen, 1998; Obermiller \& Spangenberg, 1998; Pirsch, Gupta, \& Grau, 2007). Skepticism has been found to be negatively associated with attitudes toward CRM campaigns in several countries, including the United States (Webb \& Mohr, 1998), China (Chang \& Cheng, 2015), Egypt (Hammad, El-Bassiouny, Paul, \& Mukhopadhyay, 2014), India (Patel et al., 2016), Malaysia (Anuar \& Mohamad, 2012), and The Netherlands (Elving, 2013). However, Youn and Kim (2008) found in a study of American consumers that "individuals high in advertising scepticism" were actually "more likely to trust a company's willingness to engage in philanthropic commitment to social causes" (p. 131). Although more studies have found a negative vs. a positive impact on CRM intentions, these conflicting findings make skepticism an interesting area of investigation for meta-analysis.

H4: Skepticism will reduce consumer intentions to purchase CRM products.

\section{Potential moderators of CRM attitudes and purchase intentions}

\section{Campaign characteristics: types of brands and causes}

\section{Real vs. fictitious brands}

To preserve authenticity, many researchers select actual or real causerelated ads to use in their CRM experiments (Goldsmith \& Yimin, 2014; Hadley, 2016; Landreth, 2002). These studies often feature brands from companies such as Unilever and Proctor \& Gamble which enjoy worldwide brand recognition. However, since experiments tend to measure causerelated advertising effects by comparing CRM vs. no CRM advertising, some researchers choose to create ads using fictitious brands, with the goal of avoiding any confounds to due pre-campaign brand attitudes (Folse, Grau, Moulard, \& Pounders, 2014; Hou, Du \& Li, 2008; Kim, Cheong, \& Lim, 2015). 


\section{Branded vs. generic causes}

The charitable causes that are used in cause-related advertising experiments also vary across the literature. Traditionally, cause-related campaigns partner with specific charitable organizations and include those brands in their CRM advertising. Many researchers therefore include branded causes in their experiments (Nawaz et al., 2016; Roy, 2010; Samu \& Wymer, 2009). However, this is not true in every case. Other CRM ads may simply mention a generic cause, such as breast cancer research, in their campaign to eliminate pre-campaign attitudes toward actual charitable organizations (Folse et al., 2014; Hou, 2008; Kim et al., 2015; Landreth, 2002).

RQ1: Will the effects of CRM campaigns vary for a) real vs. fictitious brands or b) branded vs. generic causes?

\section{Country of origin, sample type and year of publication}

Three additional moderators that were tested include the country of origin for the study, type of sample for the study (college participants vs non-college participants), and year of publication. Since both age and education have been found to indicate increased support for cause-related marketing campaigns (Nielsen, 2014), college student samples may react differently from non-college participants in the general consumer populations. Further, the global cultural differences in participants may also yield different reactions toward support for CRM campaigns. Lastly, since the included studies in this analysis ranged over a 30 year span, the date of study will also be examined as a potential moderator.

RQ2: Will the effects of CRM advertising campaigns vary globally for a) Western vs. Non-Western countries, b) Western vs. Asian countries?

RQ3: Will the effects of CRM advertising campaigns vary for a) for college vs non-college participants or b) by date of study?

\section{Measurement of cause-brand fit and cause involvement}

\section{Measurement of cause-brand fit}

Early definitions of brand-alliances (Aaker \& Keller, 1990; Simonin \& Ruth, 1998) used primarily categorical measures of fit, where pretest respondents are asked to react to manipulated brand alliances and categorize them as high, medium or low fit. Decades later, many researchers continue to use this manipulated levels of fit approach for CRM (Elving, 2013; Folse et al., 2014; Kim et al., 2015; Landreth, 2002; Roy, 2010; Samu \& Wymer, 2009; Sheikh \& 
Beise-Zee, 2011). More recently, cause-related marketing scholars are adopting continuous measurement techniques for cause-brand fit (Ellen, Web, \& Mohr, 2006; Goldsmith \& Yimin, 2014; Hadley, 2016; Sabir et al., 2014; Steckstor, 2011; Westberg \& Pope, 2014; Zdravkovic, Magnusson, \& Stanley, 2010)

\section{Measurement of cause involvement}

In cause-related marketing studies, involvement with the cause is also determined using both dichotomized categorical measures (Grau \& Folse, 2007; Hou, 2008, Landreth, 2002) and with semantic differential scales (Aggarwal \& Singh, 2017; Berger et al., 1999; Chang, 2012b; Hyllegard et al., 2010; Kumar \& Bansal, 2017; Patel et al., 2016.)

RQ4: Will the effects of cause-related marketing campaigns vary by type of measurement (scale vs categorical) for a) cause-brand fit or b) cause involvement?

\section{Method}

\section{Selection criteria for inclusion of studies}

A search of the available literature was conducted to identify as many relevant CRM studies as possible to contribute to this meta-analysis. Studies were accepted from any country, in any language, as an article published in peer-reviewed journal or as a dissertation or thesis. The goal of the search was to find any mediated CRM study that used consumer attitudes or purchase intentions as the dependent variable. The following is a detailed description of the literature search, in adherence with PRISMA meta-analysis guidelines (Moher, Liberati, Tetzlaff, \& Altman, 2009).

\section{Search procedure}

A Boolean search was conducted in September, 2017 in the following databases: Communication \& Mass Media Complete, JSTOR, ProQuest ABI/Inform Global, ProQuest Dissertations \& Theses, PsycINFO, and Scopus. The search engine Google Scholar was also used as a redundant measure and to identify as many global studies as possible. Search results were filtered to eliminate campaigns that did not a) contain a cause-related marketing message, b) contain any type of advertising or marketing message, $c$ ) measure any variety of consumer attitudes or purchase intentions as the dependent variable, or d) involve a specific cause-brand purchase. The unit of analysis was the CRM advertising campaign. To be included in the analysis, the CRM needed to include a consumer exchange - campaigns that sponsored events or general philanthropic activities were excluded as they do not meet the definition of CRM by Varadarajan and Menon (1988) presented in the introduction. 
In total, 43 studies were selected for the analysis from 15 countries, $\mathrm{N}=22,436$ (Table 1).

\section{Coding and data extraction}

Articles were coded by the following characteristics: first author, year of publication, type of publication, location of study, and experimental method. CRM advertising campaigns were coded by type of cause, and product or brand. Participants in each experiment and control group were coded by sample size, age, and gender. Independent variables used in each study were coded by measurement type to facilitate a comparison between the effect sizes from categorical measures vs the effect sizes from continuous measures. The effect sizes for dependent variables attitudes and purchase intentions were coded by statistics provided by the authors, including means, standard deviations, betas and/or correlations.

\section{Intercoder reliability}

Two coders extracted effect sizes and used an in-person review process that included consultation to resolve disagreements and assure consensual validation. Studies with missing data that could not be found through correspondence with the authors were eliminated from the analysis. Intercoder reliability was calculated using Krippendorff's alpha to determine percentage of agreement for each category taking into account agreement that happens

Table 1. List of included studies by country.

\begin{tabular}{ll}
\hline Country & \multicolumn{1}{c}{ Included Studies } \\
\hline United States (15) & Arora and Henderson (2007), Bae (2016), Folse et al. (2014), Goldsmith and \\
& Yimin (2014), Grau and Folse (2007), Hadley (2016), Hyllegard, Ogle, Yan, \\
& and Attmann (2010), Hyllegard et al. (2010), Kerr and Das (2013), Kim et al. \\
& (2015), Lafferty (2009), Landreth (2002), Manuel, Youn, and Yoon (2014), Nan \\
& and Heo (2007), Roy (2010), and Zdravkovic et al. (2010). \\
Australia (3) & Berger et al. (1999) and Westberg and Pope (2005, 2014). \\
Canada (1) & Samu and Wymer (2009). \\
China (2) & Chang (2012b) and Hou et al. (2008) \\
Egypt (1) & Hammad et al. (2014) \\
Germany (2) & Boenigk and Schuchardt (2013) and Steckstor (2011). \\
India (3) & Aggarwal and Singh (2017), Kumar and Bansal (2017) and Patel et al. (2016) \\
Netherlands (1) & Elving (2013). \\
New Zealand (1) & Hamiln and Wilson (2004). \\
Pakistan (4) & Nawaz et al. (2016), Sabir et al. (2014), Shabbir, Kaufmann, Ahmad, and \\
& Qureshi (2010) and Sheikh and Beise-Zee (2011). \\
Singapore (1) & Subrahmanyan (2004). \\
South Africa (1) & Engelbrecht and Du Plessis (2004). \\
South Korea (3) & Ham and Choi (2012), Kim (2014) and Seok Sohn, Han, and Lee (2012). \\
Spain (3) & Bigné-Alcañiz et al. (2012), García-Jiménez, Ruiz-de-Maya, and López-López \\
Taiwan (2) & (2017) and Melero and Montaner (2016). \\
\hline
\end{tabular}


merely by chance (Krippendorff, 2004). After the coding of studies was completed, intercoder reliability between the two coders was determined. Reliability for the following meta-analyses ranged from $\alpha=.770$ to .861 , exceeding the recommendation for sufficiently reliable findings, $\alpha \leq .70$ (Krippendorff, 2004).

\section{Meta-analytic procedure}

Effect sizes were computed using a random-effects model to allow that the true effect size might vary from one study to another, as found in the meta-analyses of communication effects research (Preiss, 2007), and to estimate the parameter mean and identify the presence of outliers (Hayes, Slater, \& Snyder, 2008). Using the standardized difference of sample means obtained through coding, the Pearson product-moment correlation coefficient, represented as $r$, was calculated to determine the effect sizes for the dependent measures in the analysis (Card, 2010). The analytical software, Comprehensive Meta-Analysis 2014, third edition, was used for effect size calculations. Positive correlations indicated that the CRM campaign variable increased attitudes and/or purchase intentions. Bivariate meta-analyses were conducted for groups of studies with common effect sizes. Effect sizes were weighted by their inverse variance, and combined using random effects meta-analytic procedures (Lipsey \& Wilson, 2001). Reporting statistics included the test for homogeneity, $Q$, the $\mathrm{I}^{2}$ index, and $95 \%$ confidence intervals (Huedo-Medina, Sánchez-Meca, Martín-Martínez, \& Botella, 2006) to examine if the proportion of variance between studies is due to more than sampling error.

\section{Detection of errors and bias}

Given that virtually no study can be deemed methodologically perfect, it is important to attempt to identify and eliminate biases and other errors in study findings, which are to be considered artifacts. Removing these artifacts, or errors that originate from imperfections in the study, not from the underlying relationships that are of scientific interest (Rubin, 1990), is an essential step in the development of valid accumulated knowledge (Cooper, Hedges, \& Valentine, 2009). Attenuation is of particular interest in meta-analysis as it refers to the "reduction or downward bias in the observed magnitude of an effect size produced by methodological limitations in a study such as measurement error or range restriction" (p. 573). In addition, this meta-analysis seeks to address the problem of inconsistent measurement of the construct cause-brand fit. The measurement of cause-brand fit and cause involvement (categorical vs continuous) varies widely across the literature (Guerreiro et al., 2015; Lafferty et al., 2016), perhaps due in part to attenuation from range restriction with some of those categorical measures (Cohen, Cohen, West, \& Aiken, 2003, p. 56). 


\section{Publication bias}

Publication bias refers to the assumption that larger studies with significant findings are more likely to be submitted for publication. The presence of publication bias was determined using a Fisher's Z (transformation of $r$ ) which compares studies of different sample sizes (Card, 2010). No such bias was detected for the meta-analyses conducted.

\section{Results}

\section{Bivariate meta-analyses}

To determine the effects of cause-related advertising, individual metaanalyses were conducted to calculate the random effect size for exposure to CRM advertising on attitude toward the brand (vs. exposure to a brandonly message), Meta-analysis $1, K=10, N=3,494$ (Table 2), and exposure to advertising on purchase intentions (vs. exposure to a brand-only message), Meta-analysis 2, $K=10, N=2,745$ (Table 3). Both used CMA software, 2014, third edition (Borenstein, Hedges, Higgins, \& Rothstein, 2009).

\section{CRM effects on attitudes}

The results of Meta-analysis $1(K=10, N=3,494)$ include a high degree of heterogeneity among studies, $Q=72.57, d f=9, p<.001, I^{2}=87.60, \tau=.146$. The random effect size $r=.248,95 \% \mathrm{CI}(.189, .373)$, confirmed a positive relationship for CRM campaigns on attitudes toward the brand, as the effects are positive and the confidence intervals do not include zero (Table 2).

Hypothesis 1a, which predicted that cause-related advertising campaigns will increase favorable consumer attitudes toward sponsoring brands, is therefore supported.

\section{Moderators of CRM effects on attitudes}

Next, meta-regressions were conducted separately to test for the moderating effect of study characteristics on the ES for CRM campaigns on attitudes toward the brand in Meta-analysis 1, including date of study, effect type (beta versus correlation), sample type (college versus consumers), brand type (fictitious versus real), cause (generic versus branded), age and gender of the participants. No significant moderating effects were found for these study characteristics.

\section{CRM effects on purchase intentions}

The results of Meta-analysis $2(K=10, N=2,745)$ also found a high degree of heterogeneity among studies, $Q=118.47, d f=9, p<.001, I^{2}=92.40, \tau=.219$. The random effect size $r=.277,95 \% \mathrm{CI}(.141, .404)$, confirmed a positive 
Table 2. Meta-analysis 1: CRM campaigns on attitudes toward the brand*.

\begin{tabular}{lcllcc}
\hline Study & Date & First Author & Country & Sample Size & Effect Size $(r)$ \\
\hline 6 & 2004 & Engelbrecht & South Africa & 204 & .387 \\
10 & 2005 & Westberg & Australia & 97 & .501 \\
15 & 2007 & Nan & USA & 100 & .128 \\
16 & 2007 & Arora & USA & 660 & .141 \\
17 & 2007 & Arora & USA & 660 & .110 \\
30 & $2010 a$ & Hyllegard & USA & 562 & .200 \\
39 & 2012 & Seok Sohn & South Korea & 304 & .176 \\
41 & 2012 & Bigné-Alcañiz & Spain & 595 & .430 \\
45 & 2012 & Ham & South Korea & 100 & .379 \\
66 & 2016 & Patel & India & 212 & .397 \\
\hline
\end{tabular}

*Random effect size $r=.248, Q=72.57, d f=9, p<.001, l^{2}=87.60, \tau=.146, K=10, N=3,494$.

Krippendorff's $a=.846$.

Table 3. Meta-analysis 2: CRM campaigns on purchase intentions*.

\begin{tabular}{llllcc}
\hline Study & Date & First Author & Country & Sample Size & Effect Size $(r)$ \\
\hline 7 & 2004 & Hamiln & New Zealand & 320 & .100 \\
8 & 2004 & Subrahmanyan & Singapore & 128 & .313 \\
10 & 2005 & Westberg & Australia & 97 & .054 \\
16 & 2007 & Arora & USA & 660 & .152 \\
17 & 2007 & Arora & USA & 660 & .105 \\
27 & 2010 & Shabbir & Pakistan & 203 & .425 \\
42 & 2013 & Boenigk & Germany & 241 & .267 \\
45 & 2012 & Ham & South Korea & 100 & .238 \\
66 & 2016 & Patel & India & 212 & .699 \\
70 & 2016 & Bae & USA & 124 & .270 \\
\hline
\end{tabular}

*Random effect size $r=.277, Q=118.47, d f=9, p<.001, I^{2}=92.40, \tau=.219, K=10, N=2,745$.

Krippendorff's $a=.795$.

relationship for CRM campaigns on purchase (Table 3). Hypothesis 1b, which predicted that cause-related advertising campaigns will increase purchase intentions, is therefore supported.

\section{Moderators of CRM effects on purchase intentions}

Meta-regressions were conducted to test for the moderating effect of study characteristics one by one on the ES for CRM campaigns on purchase intentions in Meta-analysis 2. A significant effect was found for date of study $(\beta=.034, p<.006)$ which explained over $50 \%$ of the variance in the analysis, $R^{2}=.51$, reducing the tau for the meta-analysis ES from $\tau=.219$ to $\tau=.048$, providing a partial answer to research question RQ3b. This small but significant effect indicates that more recent studies have larger effect size than older studies, perhaps due to an increase in familiarity of CRM campaigns by participants.

In addition, a significant effect $\left(\beta=-.219, p<.008, R^{2}=.76\right)$ was found for the type of participants in the sample, $(1=$ College, $2=$ Consumer $)$, indicating a larger effect for CRM on purchase intentions for college-aged participants than for participants in consumer studies open to all ages over 18 , providing a partial answer to research question RQ3a. Note that only two 
studies in Meta-analysis $2(\mathrm{~K}=10)$ provided a mean age for study participants, therefore, the study characteristic age could not be used as a moderator.

\section{Cause-brand fit effects on attitudes}

Meta-analysis 3 (Table 4) was conducted to examine the effect of cause-brand fit on attitude toward the brand. Meta-analysis 4 (Table 5) was conducted to examine the effect of cause-brand fit on purchase intentions. The results of Meta-analysis $3(K=14, N=4,641)$ found a moderate degree of heterogeneity among studies, $Q=74.124, d f=13, p<.001, I^{2}=82.462, \tau=.126$ (Table 4).The random effect size $r=.239,95 \% \mathrm{CI}(0.167,0.309)$, confirmed a positive relationship for cause-brand fit on attitude toward sponsoring brands, supporting Hypothesis 2a.

\section{Moderating effect of measurement}

A meta-regression was conducted to test for the moderating effect of causebrand fit measurement. The results were not significant $(\beta=.016, p<.866$, $R^{2}=0$ ), partially answering the research question RQ4a, measurement type does not moderate the effect of cause-brand fit on brand attitudes for this group of studies. Therefore, it can be concluded that no effect for range restriction occurred in Meta-analysis 3. Note that the study characteristic cause-brand fit measurement was also tested as a moderator of the effect of cause-brand fit on purchase intentions (see Meta-analysis 4, Table 5) with insignificant results, confirming research question RQ4a, measurement type does not moderate the effect of cause-brand fit on purchase intentions either. No significant moderating effects were found for any other study characteristics.

Table 4. Meta-analysis 3: cause-brand fit on attitude toward brand*.

\begin{tabular}{llllccc}
\hline Study & Date & First Author & \multicolumn{1}{c}{ Country } & Sample Size & Fit $^{* *}$ & Effect Size $(r)$ \\
\hline 4 & 2002 & Landreth & USA & 474 & 1 & .064 \\
21 & 2009 & Samu & Canada & 240 & 1 & .500 \\
22 & 2009 & Samu & Canada & 120 & 1 & .309 \\
24 & 2009 & Lafferty & USA & 170 & 1 & .031 \\
31 & 2011 & Steckstor & Germany & 1463 & 2 & .182 \\
32 & 2011 & Sheikh & Pakistan & 203 & 1 & .274 \\
43 & 2013 & Elving & The Netherlands & 160 & 1 & .240 \\
52 & 2014 & Folse & USA & 205 & 1 & .159 \\
56 & 2015 & Kim & USA & 156 & 1 & .259 \\
57 & 2015 & Kim & USA & 127 & 1 & .361 \\
62 & 2014 & Westberg & Australia & 135 & 2 & .177 \\
73 & 2010 & Roy & USA & 176 & 1 & .155 \\
79 & 2016 & Melero & Spain & 186 & 1 & .216 \\
72 & 2010 & Zdravkovic & USA & 826 & 2 & .371 \\
\hline
\end{tabular}

*Random effect size $r=.239, Q=74.124, d f=13, p<.001, I^{2}=82.462, \tau=.126, K=14, N=4,641$. ${ }^{* *}$ Cause-brand fit coded $1=$ dichotomized measure, $2=$ scale measure. Krippendorff's $a=.861$. 


\section{Cause-brand fit effects on purchase intentions}

The next bivariate meta-analysis was conducted to calculate the effect of cause-brand fit on purchase intentions (Table 5). The results of Meta-analysis $4(K=12, N=3,578)$ found a high degree of heterogeneity among studies, $Q=140.542, d f=11, p<.001, I^{2}=92.173, \tau=.203$. The mean correlation assuming random effects was $r=.319,95 \% \mathrm{CI}(0.206,0.423)$; this confirmed Hypothesis 2b, a positive effect of cause-brand fit on purchase intentions (Table 5).

\section{Moderating effect of measurement}

A meta-regression was again conducted to test for the moderating effect of cause-brand fit measurement. The results were not significant $(\beta=.126$, $p<.327, R^{2}=0$ ), indicating that measurement type does not moderate the effect of cause-brand fit on purchase intentions for this group of studies, further confirming a negative answer for research question RQ4a. Therefore, it can be concluded that no effect for range restriction occurred in Metaanalysis 4 . No significant moderating effects were found for these study characteristics.

\section{Cause involvement effects on attitudes}

Meta-analyses 5 (Table 6) examined the effects of cause-involvement on attitudes toward the brand. Meta-analysis $5(K=9, N=4,420)$ results also found a high degree of heterogeneity, $Q=64.728$, $d f=8, p<.001$, $I^{2}=87.641, \tau=.126$ (Table 6). The random effect size found in the analysis $r=.270,95 \% \operatorname{CI}(0.185,0.352)$, confirmed a positive relationship for cause involvement on attitude toward the sponsoring brand, thus Hypothesis $3 \mathrm{a}$ is supported.

Table 5. Meta-analysis 4: cause-brand fit on purchase intentions*.

\begin{tabular}{llllccc}
\hline Study & Date & First Author & Country & Sample Size & Fit $^{* *}$ & Effect Size $(r)$ \\
\hline 4 & 2002 & Landreth & USA & 474 & 1 & .207 \\
19 & 2008 & Hou & China & 376 & 2 & .691 \\
21 & 2009 & Samu & Canada & 240 & 1 & .291 \\
22 & 2009 & Samu & Canada & 120 & 1 & .389 \\
48 & 2013 & Kerr & USA & 216 & 1 & .309 \\
53 & 2014 & Goldsmith & USA & 604 & 2 & .210 \\
54 & 2014 & Sabir & Pakistan & 423 & 2 & .341 \\
55 & 2014 & Kim & South Korea & 240 & 1 & .176 \\
57 & 2015 & Kim & USA & 127 & 1 & .377 \\
67 & 2016 & Hadley & USA & 515 & 2 & .177 \\
71 & 2016 & Nawaz & Pakistan & 67 & 2 & .408 \\
73 & 2010 & Roy & USA & 176 & 1 & .145 \\
\hline
\end{tabular}

*Random effect size $r=.319, Q=140.542, d f=11, p<.001, l^{2}=92.173, \tau=.203, K=12, N=3,578$. ${ }^{* *}$ Cause-brand fit coded $1=$ dichotomized measure, $2=$ scale measure. Krippendorff's $a=.783$. 
Table 6. Meta-analysis 5: cause involvement on attitude toward brand*.

\begin{tabular}{lcllccc}
\hline Study & Date & First Author & Country & Sample Size & Inv $^{* *}$ & Effect Size $(r)$ \\
\hline 1 & 1999 & Berger & Australia & 196 & 2 & .340 \\
2 & 1999 & Berger & Australia & 210 & 2 & .150 \\
4 & 2002 & Landreth & USA & 474 & 1 & .202 \\
30 & $2010 \mathrm{a}$ & Hyllegard & USA & 562 & 2 & .120 \\
31 & 2011 & Steckstor & Germany & 1463 & 2 & .359 \\
34 & 2012 & Chang, C. & Taiwan & 128 & 2 & .550 \\
66 & 2016 & Patel & India & 212 & 2 & .183 \\
72 & 2010 & Zdrakovic & USA & 826 & 2 & .367 \\
81 & $2010 \mathrm{~b}$ & Hyllegard & USA & 349 & 2 & .150 \\
\hline
\end{tabular}

*Random effect size $r=.270, Q=64.728, d f=8, p<.001, I^{2}=87.641, \tau=.126, K=9, N=4,420$.

${ }^{* *}$ Cause involvement measures coded $1=$ dichotomized, $2=$ scale. Krippendorff's $a=.770$.

\section{Moderating effect of measurement}

A meta-regression conducted to test for the moderating effect of cause involvement measurement. The results were not significant $(\beta=.083$, $p<.580, R^{2}=0$ ), indicating that measurement type does not moderate the effect of cause involvement on attitude toward the brand for this group of studies, thus, answering research question RQ4b. Therefore, it can be concluded that not unlike the measurement of cause-brand fit on attitude toward the brand and purchase intentions in Meta-analyses 3 and 4 respectively, range restriction does not affect the positive relationship between cause involvement and attitude toward the brand. Other study characteristics tested for Meta-analysis 5 did not have a significant effect on the ES for cause involvement on attitude toward the brand.

\section{Cause involvement effects on purchase intentions}

Meta-analyses 6 (Table 7) examined the effects of cause-involvement on attitudes toward the brand. The results of Meta-analysis $6(K=10$, $N=2,645)$ found a high degree of heterogeneity among studies, $Q=90.499$, $d f=9, p<.001, I^{2}=90.055, \tau=.171$. The random effect size found $r=.348$, $95 \% \mathrm{CI}(0.244,0.444)$, confirmed a positive relationship for cause involvement on purchase intentions (Table 7), thus supporting Hypothesis $3 \mathrm{~b}$.

\section{Moderating effect of measurement}

Next, meta-regressions were conducted to test for the moderating effect of cause involvement measurement in Meta-analysis 6. Insignificant results were found $\left(\beta=-.043, p=.779, R^{2}=0\right.$ ), indicating that measurement type does not moderate the effect of cause involvement on purchase intentions for this group of studies either, confirming a negative answer for research question RQ4b. We can conclude that range restriction does not affect the positive relationship between cause involvement and attitude toward the brand or purchase intentions. No significant moderating effects were found for these study characteristics. 
Table 7. Meta-analysis 6: cause involvement on purchase intentions*.

\begin{tabular}{lcllccc}
\hline Study & Date & First Author & Country & Sample Size & Inv $^{* *}$ & Effect Size $(r)$ \\
\hline 1 & 1999 & Berger & Australia & 196 & 2 & .300 \\
2 & 1999 & Berger & Australia & 210 & 2 & .340 \\
4 & 2002 & Landreth & USA & 474 & 1 & .313 \\
18 & 2007 & Grau & USA & 141 & 1 & .450 \\
19 & 2008 & Hou & China & 376 & 2 & .388 \\
30 & $2010 \mathrm{a}$ & Hyllegard & USA & 562 & 2 & .120 \\
35 & 2012 & Chang, C-T & China & 369 & 2 & .240 \\
71 & 2016 & Nawaz & Pakistan & 67 & 2 & .473 \\
76 & 2017 & Kumar & India & 680 & 2 & .146 \\
77 & 2017 & Aggarwal & India & 180 & 2 & .671 \\
\hline
\end{tabular}

${ }^{*}$ Random effect size $r=.348, Q=90.499, d f=9, p<.001, I^{2}=90.055, \tau=.171, K=10, N=4,420$.

${ }^{* *}$ Cause involvement measures coded $1=$ dichotomized, $2=$ scale. Krippendorff's $a=.770$.

\section{Skepticism effects on purchase intentions}

Finally, Meta-analysis 7 calculated the effect of skepticism on purchase intentions (see Table 8). Although the number of studies able to test the relationship was low, $(K=5, N=913)$ there was a small degree of heterogeneity among studies, $Q=7.96, d f=4, p=.093, I^{2}=49.746, \tau=.076$. The random effect size $r=-0.319,95 \% \mathrm{CI}(-0.403,-0.230)$, confirmed a negative relationship for skepticism on purchase intentions, supporting Hypothesis 4.

\section{Moderating effects of skepticism on purchase intentions}

A meta-regression analysis found a significant effect for the study characteristic sample type $(1=$ College, $2=$ Consumer $), \beta=-.15, p<.027$. This finding explained virtually all of the variance in the ES for skepticism on purchase intentions, $R^{2}=.99$, with a reduction in Tau from $\tau=.076$ to $\tau=.007$. Thus, partially answering RQ3a, the effect for college participants is less than the effect of skepticism on purchase intentions for consumer participants. No significant moderating effect was found for country of origin through subgroup analysis - Western vs. non-Western or Western vs Asian or any other study characteristics. This is unsurprising given the relative homogeneity of the studies. Note, however, the results of a meta-regression with a small number of studies $(K<10)$ should be viewed with caution, as the power may be insufficient given the number of predictors (Schmidt \& Hunter, 2014). Therefore we cannot conclusively answer the research

Table 8. Meta-analysis 7: skepticism on purchase intentions*.

\begin{tabular}{llllcc}
\hline Study & Date & First Author & Country & Sample Size & Effect Size $(r)$ \\
\hline 43 & 2013 & Elving & The Netherlands & 160 & -.340 \\
59 & 2014 & Hammad & Egypt & 261 & -.377 \\
63 & 2014 & Manuel & USA & 81 & -.300 \\
74 & 2015 & Chang & Taiwan & 291 & .190 \\
78 & 2017 & García-Jiménez & Spain & 120 & -.410 \\
\hline
\end{tabular}

${ }^{*}$ Random effect size $r=-.319, Q=7.96, d f=4, p<.093, I^{2}=49.746, \tau=.076$, Krippendorff's $a=.795 K=5$, $N=913$. 
question RQ2 of whether CRM effects vary for global consumers by region, but the limited evidence from Meta-analysis $7(K=5, N=913)$ suggests that skepticism toward cause-related advertising campaigns is similar for global consumers.

\section{Moderating effects of brand and cause type}

Lastly, each study was coded by type of CRM experiment brand (fictitious $=1$, real $=2$ ) and cause (generic $=1$, specific NPO $=2$ ). Again, no significant moderating effect was found for any of the bivariate meta-analyses conducted. The same finding holds for the use of generic causes vs. branded causes in studies, thus providing a negative answer for research question RQ1a and b, respectively.

\section{Discussion}

The effect sizes calculated by the seven individual meta-analyses (Table 9) will guide future cause-related advertising campaign and CRM studies, and are consistent with effects found in previous literature reviews (Guerreiro et al., 2015; Lafferty et al., 2016; Natarajan et al., 2016). Further, all of the hypothesized main effects (Table 9) held, as none of the study characteristics examined in the moderator analyses altered the direction of those relationships.

\section{Examining for attenuation-induced biases}

Range restriction. The issue of range restriction was explored by Metaanalysis 3 and Meta-analysis 4 (cause-brand fit) as well as Meta-analysis 5 and Meta-analysis 6 (cause involvement) through the coding of continuous and dichotomous measurement. When examined as a possible moderating study characteristic, no significant effect was found for measurement type. In addition, all studies were coded for type of effect size coefficient (Beta $=1$, correlation $=2$ ). No significant effect was found for type of effect in any of these meta-analyses.

Table 9. Summary of findings: effect sizes by meta-analysis.

\begin{tabular}{lrrcc}
\hline Meta-analysis & \multicolumn{1}{c}{$\mathrm{K}$} & $\mathrm{N}$ & $\mathrm{ES}(\mathrm{r})$ fixed & random* $^{*}$ \\
\hline 1.CRM on Attitudes toward Brand & 10 & 3,494 & $.284(.217, .279)$ & $.248(.189, .373)$ \\
2.CRM on Purchase Intentions & 10 & 2,745 & $.232(.196, .267)$ & $.277(.141, .404)$ \\
3.Cause-Brand Fit on Attitudes toward Brand & 14 & 4,641 & $.234(.207, .261)$ & $.239(.167, .309)$ \\
4.Cause-Brand Fit on Purchase Intentions & 12 & 3,578 & $.305(.275, .335)$ & $.319(.206, .423)$ \\
5.Cause Involvement on Attitudes toward Brand & 9 & 4,420 & $.287(.260, .314)$ & $.270(.185, .352)$ \\
6.Cause Involvement on Purchase Intentions & 10 & 2,645 & $.286(.254, .318)$ & $.348(.244, .444)$ \\
7.Skepticism on Purchase Intentions & 5 & 913 & $-.311(-.368,-.250)$ & $-.319(-.403,-230)$ \\
\hline
\end{tabular}

*95\% confidence intervals presented below ES. Total $N=22,436$. 


\section{Limitations}

Several limitations that occurred over the course of this meta-analysis research may have influenced its results. Several studies were excluded from the analysis due to missing data, particularly in older studies. Authors were emailed but may not have the same contact information given the passage of time. Although the "file drawer problem" has been minimized in the advent of online publishing, there are undoubtedly many unpublished studies that have been omitted. In addition, new studies may have been published in the months since the search concluded and the analysis began.

\section{Checkout charities}

According to a report by Engage for Good, these check-out charity campaigns are on the rise, reaching $\$ 441$ million in 2016, up from $\$ 348$ million in 2012 (Engage for Good, 2017). These point-of-purchase CRM programs, also known as checkout charity programs (Giebelhausen, Lawrence, Chun, and Hsu (2017), were not included in this analysis as they do not include a mediated message. However, these CRM programs should be examined in future research, as their effect sizes will provide an informative comparison to mediated programs. Check-out programs should yield smaller effect sizes, given the effect of CRM campaign messages on brand attitudes $(r=.248)$ found in Meta-analysis 1 , and the effect of CRM campaign messages on purchase intentions $(r=.277)$ found in Meta-analysis 2 .

\section{Recommendations for future CRM advertising campaigns}

Brand marketers should carefully choose their, causes, given that consumer cause involvement, had the largest effect $(r=.348)$ on CRM purchase intentions in this study. Brand marketers should also embrace a wider range of causes, as consumers are already shifting in this direction, supporting health, hunger and social services, through retail check-out programs (Engage for Good, 2017).

\section{Choosing alliances}

Selecting the right brand to align with their cause is an important and challenging decision for charities, as the impact of cause-brand fit on purchase intentions was the second-largest ES found in this study $(r=.319)$. Unfortunately for these nonprofit organizations, none of the six metaanalyses conducted found any effect for the study characteristic, type of cause (generic or branded company). Thus, the contribution of a specific branded cause (e.g. heart disease vs American Heart Association) does not appear to have a significant impact on consumers. 


\section{Recommendations for future academic research}

Given that the bivariate meta-analyses conducted found no significant difference for the study characteristic type of brand (real or fictitious), academic researchers should feel free to use either type of message. This is an interesting finding for CRM studies, as many researchers take extra time and effort to create fictitious brands in their experiments to eliminate any influence of prior brand attitude. Since no evidence was found for this point-ofview in any of the six meta-analyses conducted. Thus, experiments can use either real or fictitious brands and achieve virtually identical results.

Further, when examined as a possible moderating study characteristic, no significant effect was found for measurement type (continuous and dichotomous measurement) for the variables cause-brand fit or cause involvement. In addition, it should be noted that correlations were the dominant effect type (71\%) found in the literature search, which were primarily calculated from analysis of variance (ANOVA) results. Future researchers of CRM advertising campaigns should also consider structural equation modeling (SEM) to better understand the relationships between these variables, especially the relationship between skepticism and perceptions of cause-brand fit for global consumers.

\section{Disclosure statement}

No potential conflict of interest was reported by the authors.

\section{ORCID}

Michelle M. Rego (1) http://orcid.org/0000-0002-2942-7249

Mark A. Hamilton (D) http://orcid.org/0000-0001-7479-0162

\section{References}

Aaker, D. A., \& Keller, K. L. (1990). Consumer evaluations of brand extensions. The Journal of Marketing, 54, 27-41. doi:10.1177/002224299005400102

Aggarwal, V., \& Singh, V. K. (2017). Cause-related marketing in India: Effect of cause involvement on purchase intention. Technological and Managerial Strategies for Next Generation Transformation, 485.

Ajzen, I. (1985). From intentions to actions: A theory of planned behavior. In J. Kuhl \& J. Beckman (Eds.), Action-control: From cognition to behavior (pp. 11-39).

Ajzen, I., \& Fishbein, M. (1980). Understanding attitudes and predicting social behaviour. Englewood Cliffs, NJ: Prentice Hall.

Anuar, M. M, \& Mohamad, O. (2012). Effects of skepticism on consumer response toward cause-related marketing in malaysia. International Business Research, 5(9), 98.

Armitage, C. J., \& Conner, M. (2001). Efficacy of the theory of planned behaviour: A metaanalytic review. British Journal of Social Psychology, 40(4), 471-499. doi:10.1348/ 014466601164939 
Arora, N., \& Henderson, T. (2007). Embedded premium promotion: Why it works and how to make it more effective. Marketing Science, 26(4), 514-531. doi:10.1287/mksc.1060.0247

Bae, M. (2016). Effects of various types of Cause-Related Marketing (CRM) ad appeals on consumers' visual attention, perceptions, and purchase intentions. Journal of Promotion Management, 22(6), 810-834. doi:10.1080/10496491.2016.1214210

Barnes, N. G. (1991). Joint venture marketing: A strategy for the 1990s. Health Marketing Quarterly, 9(1-2), 23-36. doi:10.1300/J026v09n01_03

Berger, I. E., Cunningham, P. H., \& Kozinets, R. V. (1999). Consumer persuasion through cause-related advertising. NA-Advances in Consumer Research, 26.

Bigné-Alcañiz, E., Currás-Pérez, R., Ruiz-Mafé, C., \& Sanz-Blas, S. (2012). Cause-related marketing influence on consumer responses: The moderating effect of cause-brand fit. Journal of Marketing Communications, 18(4), 265-283. doi:10.1080/13527266.2010.521358

Boenigk, S, \& Schuchardt, V. (2013). Cause-related marketing campaigns with luxury firms: an experimental study of campaign characteristics, attitudes, and donations. International Journal Of Nonprofit and Voluntary Sector Marketing, 18(2), 101-121.

Boenigk, S., \& Schuchardt, V. (2013). Cause-related marketing campaigns with luxury firms: An experimental study of campaign characteristics, attitudes, and donations. International Journal of Nonprofit and Voluntary Sector Marketing, 18(2), 101-121. doi:10.1002/ nvsm. 1452

Borenstein, M, Hedges, L. V, Higgins, J P, \& Rothstein, H. R. (2009). Fixed-effect versus random-effects models. Introduction to Meta-analysis, 77, 85.

Caesar, P. (1986). Cause related marketing: A new face of corporate philanthropy. Business and Society Review, 59, 15-19.

Card, N. A. (2010). Applied meta-analysis for social science research. New York, NY: Guilford Publications.

Chang, C. (2012a). The effectiveness of advertising that leverages sponsorship and cause-related marketing: A contingency model. International Journal of Advertising, 31 (2), 317-338. doi:10.2501/IJA-31-2-317-337

Chang, C. T. (2012b). Missing ingredients in cause-related advertising: The right formula of execution style and cause framing. International Journal of Advertising, 31(2), 231-256. doi:10.2501/IJA-31-2-231-256

Chang, C. T., \& Cheng, Z. H. (2015). Tugging on heartstrings: Shopping orientation, mindset, and consumer responses to cause-related marketing. Journal of Business Ethics, 127(2), 337-350. doi:10.1007/s10551-014-2048-4

Chang, C. T, \& Liu, H. W. (2012). Goodwill hunting? influences of product-cause fit, product type, and donation level in cause-related marketing. Marketing Intelligence \& Planning, 30 (6), 634-652.

Cohen, J. (1992). A power primer. Psychological Bulletin, 112(1), 155. doi:10.1037/00332909.112.1.155

Cohen, J., Cohen, P., West, S. G., \& Aiken, L. S. (2003). Applied multiple regression/correlation analysis for the behavioural sciences (3rd ed.). Mahwah, NJ: Lawrence Erlbaum.

Cone. (2017). Cone communications CSR study. Retrieved from http://www.conecomm.com/ 2017-cone-communications-csr-study-pdf

Cooper, H., Hedges, L. V., \& Valentine, J. C. (Eds.). (2009). The handbook of research synthesis and meta-analysis. Russell Sage Foundation, New York.

Ellen, P. S., Mohr, L. A., \& Webb, D. J. (2000). Charitable programs and the retailer: Do they mix? Journal of Retailing, 76(3), 393-406. doi:10.1016/S0022-4359(00)00032-4

Ellen, P. S, Webb, D. J, \& Mohr, L. A. (2006). Building corporate associations: consumer attributions for corporate socially responsible programs. Journal Of The Academy of Marketing Science, 34(2), 147-157. doi:10.1177/0092070305284976 
Elving, W. J. (2013). Scepticism and corporate social responsibility communications: The influence of fit and reputation. Journal of Marketing Communications, 19(4), 277-292. doi:10.1080/13527266.2011.631569

Engage for Good. (2017). America's charity checkout champions. Retrieved from http:// engageforgood.com/ccc2017/

Engelbrecht, M., \& Du Plessis, P. J. (2004). The effects of cause-related marketing and cause importance on consumers' attitudes towards products and brands. Management Dynamics: Journal of the Southern African Institute for Management Scientists, 13(4), 2-14.

Fishbein, M. (1963). An investigation of the relationships between beliefs about an object and the attitude toward that object. Human Relations, 16(3), 233-239. doi:10.1177/ 001872676301600302

Fishbein, M, \& Ajzen, I. (1973). Attribution of responsibility: a theoretical note. Journal of Experimental Social Psychology, 9(2), 148-153. doi:

Folse, J. A. G., Grau, S. L., Moulard, J. G., \& Pounders, K. (2014). Cause-related marketing: Factors promoting campaign evaluations. Journal of Current Issues \& Research in Advertising, 35(1), 50-70. doi:10.1080/10641734.2014.866847

Galan-Ladero, M. M., Galera-Casquet, C., Valero-Amaro, V., \& Barroso-Mendez, M. J. (2013). Does the product type influence on attitudes toward cause-related marketing? Economics \& Sociology, 6(1), 60. doi:10.14254/2071-789X.2013/6-1

García-Jiménez, J. V., Ruiz-de-Maya, S., \& López-López, I. (2017). Spanish Journal of Marketing-ESIC, 21, 26-38.

Giebelhausen, M., Lawrence, B., Chun, H. H., \& Hsu, L. (2017). The warm glow of restaurant checkout charity. Cornell Hospitality Quarterly, 58(4), 329-341. 1938965517704533.

Goldsmith, R. E., \& Yimin, Z. (2014). The influences of brand-consumer and cause-congruence on consumer responses to cause related marketing. Journal of Applied Marketing Theory, 5(2), 74-95.

Grau, S. L., \& Folse, J. A. G. (2007). Cause-related marketing (CRM): The influence of donation proximity and message-framing cues on the less-involved consumer. Journal of Advertising, 36(4), 19-33. doi:10.2753/JOA0091-3367360402

Guerreiro, J., Rita, P., \& Trigueiros, D. (2015). A text mining-based review of cause-related marketing literature. Journal of Business Ethics, 329(1), 111-128.

Hadley, K. M. (2016). Influences on Consumer Response to Cause-related Marketing (CRM): Privately-consumed versus publicly-consumed products. Anderson University, Indiana, U.S. A.

Hajjat, M. (2003). Effect of cause-related marketing on attitudes and purchase intentions: The moderating role of cause involvement and donation size. Journal of Nonprofit and Public Sector Marketing, 11(1), 93-109. doi:10.1300/J054v11n01_07

Ham, S., \& Choi, Y. K. (2012). Effect of cause-related marketing for green practices in the hotel industry. Journal of Global Scholars of Marketing Science, 22(3), 249-259. doi:10.1080/21639159.2012.696338

Hamiln, R. P., \& Wilson, T. (2004). The impact of cause branding on consumer reactions to products: Does product/cause 'fit' really matter? Journal of Marketing Management, 20(78), 663-681. doi:10.1362/0267257041838746

Hammad, H., El-Bassiouny, N., Paul, P., \& Mukhopadhyay, K. (2014). Antecedents and consequences of consumers' attitudinal dispositions toward cause-related marketing in Egypt. Journal of Islamic Marketing, 5(3), 414-445. doi:10.1108/JIMA-10-2013-0076

Hayes, A. F., Slater, M. D., \& Snyder, L. B. (2008). The Sage sourcebook of advanced data analysis methods for communication research. Thousand Oaks, CA: Sage. 
Hou, J., Du, L., \& Li, J. (2008). Cause's attributes influencing consumer's purchasing intention: Empirical evidence from China. Asia Pacific Journal of Marketing and Logistics, 20(4), 363-380. doi:10.1108/13555850810909704

Huedo-Medina, T. B., Sánchez-Meca, J., Martín-Martínez, F., \& Botella, J. (2006). Assessing heterogeneity in meta-analysis: Q statistic or $\mathrm{I}^{2}$ index? Psychological Methods, 11(2), 193-206. doi:10.1037/1082-989X.11.2.193

Hyllegard, K. H., Ogle, J. P., Yan, R. N., \& Attmann, J. (2010). Exploring Gen Y responses to an apparel brand's use of cause-related marketing does message matter when it comes to support for the breast cancer cause? Clothing and Textiles Research Journal, 28(1), 19-34. doi: $10.1177 / 0887302 X 09342465$

Hyllegard, K. H., Yan, R. N., Ogle, J. P., \& Attmann, J. (2010). The influence of gender, social cause, charitable support, and message appeal on Gen Y's responses to cause-related marketing. Journal of Marketing Management, 27(1-2), 100-123. doi:10.1080/ 02672571003683755

IEG. (2016). What sponsors want and where dollars will go in 2016. IEG Sponsorship Report. Retrieved from http://www.sponsorship.com/IEGSR/2016/01/05/As-Sponsorship-BordersFall,Spending-Rises.aspx

Kerr, A. H., \& Das, N. (2013). Thinking about fit and donation format in cause marketing: The effects of need for cognition. Journal of Marketing Theory and Practice, 21(1), 103-112. doi:10.2753/MTP1069-6679210107

Kim, J. (2014). The roles of cause involvement and cause acts in a social marketing campaign. Journal of Global Scholars of Marketing Science, 24(4), 426-440. doi:10.1080/ 21639159.2014.949032

Kim, K., Cheong, Y., \& Lim, J. S. (2015). Choosing the right message for the right cause in social cause advertising: Type of social cause message, perceived company-cause fit and the persuasiveness of communication. International Journal of Advertising, 34(3), 473-494. doi:10.1080/02650487.2015.1006081

Krippendorff, K. (2004). Reliability in content analysis. Human Communication Research, 30 (3), 411-433.

Kumar, D., \& Bansal, H. (2017). Influence of cause brand fit on consumers purchase intention. International Journal of Research in Finance and Marketing, 7(1), 99-107.

Lafferty, B. A. (2009). Selecting the right cause partners for the right reasons: the role of importance and fit in cause-brand alliances. Psychology \& Marketing, 26(4), 359-382. doi: 10.1002/mar.20277

Lafferty, B. A, \& Edmondson, D. R. (2009). Portraying the cause instead of the brand in cause-related marketing ads: does it really matter?. Journal Of Marketing Theory and Practice, 17(2), 129-144.

Lafferty, B. A, Goldsmith, R. E, \& Hult, G. T. M. (2004). The impact of the alliance on the partners: a look at cause-brand alliances. Psychology \& Marketing, 21(7), 509.

Lafferty, B. A., Lueth, A. K., \& McCafferty, R. (2016). An evolutionary process model of cause-related marketing and systematic review of the empirical literature. Psychology \& Marketing, 33(11), 951-970. doi:10.1002/mar.20930

Landreth, S. (2002). For a good cause: The effects of cause important, cause proximity, congruency and participation effort on consumers' evaluation of cause related marketing.

Lipsey, M. W., \& Wilson, D. B. (2001). Practical meta-analysis. SAGE publications, Inc.

Manuel, E., Youn, S., \& Yoon, D. (2014). Functional matching effect in CRM: Moderating roles of perceived message quality and scepticism. Journal of Marketing Communications, 20(6), 397-418. doi:10.1080/13527266.2012.715587

Melero, I., \& Montaner, T. (2016). Cause-related marketing: An experimental study about how the product type and the perceived fit may influence the consumer response. 
European Journal of Management and Business Economics, 25(3), 161-167. doi:10.1016/j. redeen.2016.07.001

Moher, D., Liberati, A., Tetzlaff, J., \& Altman, D. G. (2009). Preferred reporting items for systematic reviews and meta-analyses: The PRISMA statement. Annals of Internal Medicine, 151(4), 264-269. doi:10.7326/0003-4819-151-4-200908180-00135

Mohr, L. A, Eroğlu, D, \& Ellen, P. S. (1998). The development and testing of a measure of skepticism toward environmental claims in marketers' communications. Journal of Consumer Affairs, 32(1), 30-55.

Nan, X., \& Heo, K. (2007). Consumer responses to corporate social responsibility (CSR) initiatives: Examining the role of brand-cause fit in cause-related marketing. Journal of Advertising, 36(2), 63-74. doi:10.2753/JOA0091-3367360204

Natarajan, T., Balasubramaniam, S. A., \& Jublee, D. I. (2016). A journey of cause related marketing from 1988 to 2016. International Journal of Business and Management, 11(11), 247. doi:10.5539/ijbm.v11n11p247

Nawaz, J., Campus, C., Ali, M. Z., Wahab, A., Walayat, A., Khan, M. U., \& Meer, A. (2016, December 19-20). Cause's attributes influencing consumer's purchase intention: The intervening role of income level. 2nd International Multi-Discpline Conference, Gujrat, Pakistan.

Nielsen. (2014). Global consumers are willing to put their money where their heart is when it comes to goods and services from companies committed to social responsibility. Retrieved from http://www.nielsen.com/us/en/press-room/2014/global-consumers-are-willing-to-put -their-money-where-their-heart-is.html

Obermiller, C, \& Spangenberg, E. R. (1998). Development of a scale to measure consumer skepticism toward advertising. Journal Of Consumer Psychology, 7(2), 159-186.

Patel, J. D., Gadhavi, D. D., \& Shukla, Y. S. (2016). Consumers' responses to cause related marketing: Moderating influence of cause involvement and scepticism on attitude and purchase intention. International Review on Public and Nonprofit Marketing, 14(1), 1-18.

Pirsch, J, Gupta, S, \& Grau, S. L. (2007). A framework for understanding corporate social responsibility programs as a continuum: an exploratory study. Journal Of Business Ethics, $70(2), 125-140$.

Pracejus, J. W., \& Olsen, G. D. (2004). The role of brand/cause fit in the effectiveness of cause-related marketing campaigns. Journal of Business Research, 57(6), 635-640. doi:10.1016/S0148-2963(02)00306-5

Preiss, R. W. (Ed.). (2007). Mass media effects research: Advances through meta-analysis.

Rego, M. M. (2017). The impact of cause-related marketing on global consumers: A meta-analysis (Doctoral dissertation). Retrieved from https://opencommons.uconn.edu/ cgi/viewcontent.cgi ?article $=7910 \&$ context $=$ dissertations

Roy, D. P. (2010). The impact of congruence in cause marketing campaigns for service firms. Journal of Services Marketing, 24(3), 255-263. doi:10.1108/08876041011040659

Rubin, D. B. (1990). Formal mode of statistical inference for causal effects. Journal of Statistical Planning and Inference, 25(3), 279-292. doi:10.1016/0378-3758(90)90077-8

Sabir, I., Aziz, S., Mannan, A., Bahadur, W., Farooq, R., \& Akhtar, N. (2014). Cause'Attributes and consumers' purchase intention: Empirical evidence from telecommunication sector of Pakistan. International Review Of Management And Business Research, 3(1), 364-375.

Samu, S., \& Wymer, W. (2009). The effect of fit and dominance in cause marketing communications. Journal of Business Research, 62(4), 432-440. doi:10.1016/j.jbusres.2008.01.039

Schmidt, F. L, \& Hunter, J. E. (2014). Methods of meta-analysis: correcting error and bias in research findings. Sage publications. 
Seok Sohn, Y., Han, J. K., \& Lee, S. H. (2012). Communication strategies for enhancing perceived fit in the CSR sponsorship context. International Journal of Advertising, 31(1), 133-146. doi:10.2501/IJA-31-1-133-146

Shabbir, S., Kaufmann, H. R., Ahmad, I., \& Qureshi, I. M. (2010). Cause related marketing campaigns and consumer purchase intentions: The mediating role of brand awareness and corporate image. African Journal of Business Management, 4(6), 1229.

Sheikh, S. U. R., \& Beise-Zee, R. (2011). Corporate social responsibility or cause-related marketing? The role of cause specificity of CSR. Journal of Consumer Marketing, 28(1), 27-39. doi:10.1108/07363761111101921

Simonin, B. L., \& Ruth, J. A. (1998). Is a company known by the company it keeps? assessing the spillover effects of brand alliances on consumer brand attitudes. Journal Of Marketing Research, 35(1), 30-42.

Steckstor, D. (2011). The effects of cause-related marketing on customers' attitudes and buying behaviour. Gabler Verlag, Germany.

Subrahmanyan, S. (2004). Effects of price premium and product type on the choice of causerelated brands: a singapore perspective. Journal Of Product \& Brand Management, 13(2), 116-124.

Varadarajan, P. R., \& Menon, A. (1988). Cause-related marketing: A co-alignment of marketing strategy and corporate philanthropy. Journal of Marketing, 52(7), 58-74. doi:10.1177/ 002224298805200306

Webb, D. J., \& Mohr, L. A. (1998). A typology of consumer responses to cause-related marketing: From skeptics to socially concerned. Journal of Public Policy \& Marketing, 17, 226-238. doi:10.1177/074391569801700207

Westberg, K., \& Pope, N. (2005). An examination of cause-related marketing in the context of brand attitude, purchase intention, perceived fit and personal values. Proceedings of the ANZMAC 2005 conference: social, not-for-profit and political marketing, Freemantle, Australia, 5-7 December 2005 (pp. 222-230).

Westberg, K., \& Pope, N. (2014). Building brand equity with cause-related marketing: A comparison with sponsorship and sales promotion. Journal of Marketing Communications, 20(6), 419-437. doi:10.1080/13527266.2012.723025

Wymer, W., \& Samu, S. (2009). The influence of cause marketing associations on product and cause brand value. International Journal of Nonprofit and Voluntary Sector Marketing, 14(1), 1-20. doi:10.1002/nvsm.v14:1

Youn, S, \& Kim, H. (2008). Antecedents of consumer attitudes toward cause-related marketing. Journal Of Advertising Research, 48(1), 123-137.

Zaichkowsky, J. L. (1985). Measuring the involvement construct. Journal of Consumer Research, 12(3), 341-352. doi:10.1086/jcr.1985.12.issue-3

Zdravkovic, S., Magnusson, P., \& Stanley, S. M. (2010). Dimensions of fit between a brand and a social cause and their influence on attitudes. International Journal of Research in Marketing, 27(2), 151-160. doi:10.1016/j.ijresmar.2010.01.005 